\title{
Rapid, efficient, and simple motor neuron differentiation from human pluripotent stem cells
}

Daisuke Shimojo ${ }^{1,2}$, Kazunari Onodera ${ }^{1,3}$, Yukiko Doi-Torii ${ }^{1}$, Yasuharu Ishihara ${ }^{2}$, Chinatsu Hattori ${ }^{2}$, Yukino Miwa ${ }^{2}$, Satoshi Tanaka ${ }^{1,4}$, Rina Okada ${ }^{1,5}$, Manabu Ohyama ${ }^{6}$, Masanobu Shoji ${ }^{7}$, Atsushi Nakanishi ${ }^{7}$, Manabu Doyu' ${ }^{1}$ Hideyuki Okano ${ }^{2^{*}}$ and Yohei Okada ${ }^{1,2^{*}}$

\begin{abstract}
Background: Human pluripotent stem cells (hPSCs) are being applied in regenerative medicine and for the in vitro modeling of human intractable disorders. In particular, neural cells derived from disease-specific human induced pluripotent stem cells (hiPSCs) established from patients with neurological disorders have been used as in vitro disease models to recapitulate in vivo pathogenesis because neural cells cannot be usually obtained from patients themselves.

Results: In this study, we established a rapid, efficient, and simple method for efficiently deriving motor neurons from hPSCs that is useful for pathophysiological analysis and the development of drugs to treat motor neuron diseases. Treatment with GSK3 $\beta$ inhibitors during the initial phase of differentiation in combination with dual SMAD inhibition was sufficient to induce $\mathrm{PAX}^{+}$and $\mathrm{SOX}^{+}$neural progenitors within 1 week, and subsequent treatment with retinoic acid (RA) and purmorphamine, which activates sonic hedgehog $(\mathrm{SHH})$ signaling, resulted in the highly efficient induction of $\mathrm{HB}^{+}$and $\mathrm{ISL}-1^{+}$motor neurons within 2 weeks. After 4 weeks of monolayer differentiation in motor neuron maturation medium, hPSC-derived motor neurons were shown to mature, displaying larger somas and clearer staining for the mature motor neuron marker choline acetyltransferase (ChAT). Moreover, hPSC-derived motor neurons were able to form neuromuscular junctions with human myotubes in vitro and induced acetylcholine receptor (AChR) clustering, as detected by Alexa 555-conjugated a-Bungarotoxin (a-BTX), suggesting that these hPSC-derived motor neurons formed functional contacts with skeletal muscles. This differentiation system is simple and is reproducible in several hiPSC clones, thereby minimizing clonal variation among hPSC clones. We also established a system for

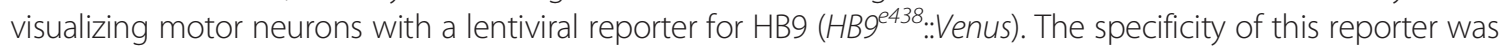
confirmed through immunocytochemistry and quantitative RT-PCR analysis of high-positive fractions obtained via fluorescence-activated cell sorting (FACS), suggesting its applicability for motor neuron-specific analysis.
\end{abstract}

Conclusions: Our motor neuron differentiation system and lentivirus-based reporter system for motor neurons facilitate the analysis of disease-specific hiPSCs for motor neuron diseases.

Keywords: Human embryonic stem cells, Human induced pluripotent stem cells, Motor neurons, Long-term culture of motor neurons, Lentiviral reporter

\footnotetext{
* Correspondence: hidokano@a2.keio.jp; yohei@aichi-med-u.ac.jp

${ }^{2}$ Department of Physiology, Keio University School of Medicine, Tokyo

160-8582, Japan

'Department of Neurology, Aichi Medical University School of Medicine,

Aichi 480-1195, Japan

Full list of author information is available at the end of the article
}

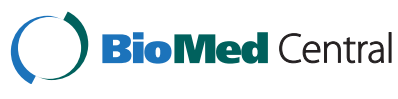

(c) 2015 Shimojo et al. Open Access This article is distributed under the terms of the Creative Commons Attribution 4.0 International License (http://creativecommons.org/licenses/by/4.0/), which permits unrestricted use, distribution, and reproduction in any medium, provided you give appropriate credit to the original author(s) and the source, provide a link to the Creative Commons license, and indicate if changes were made. The Creative Commons Public Domain Dedication waiver (http://creativecommons.org/publicdomain/zero/1.0/) applies to the data made available in this article, unless otherwise stated. 


\section{Background}

Human pluripotent stem cells (hPSCs), including human embryonic stem cells (hESCs) and human induced pluripotent stem cells (hiPSCs), can be differentiated into all cell types of the human body and have been applied in regenerative medicine and the pathophysiological analysis of intractable disorders [1]. In particular, neural cells derived from disease-specific hiPSCs from patients with neurological disorders have been especially useful as in vitro disease models recapitulating in vivo pathogenesis, as cells in the nervous system cannot be usually obtained from patients themselves.

Amyotrophic lateral sclerosis (ALS), spinal muscular atrophy (SMA), and spinal and bulbar muscular atrophy (SBMA) are motor neuron diseases. Although these motor neuron diseases exhibit different molecular pathologies, they share a common phenotype: motor neuron degeneration. To reveal the mechanisms underlying motor neuron degeneration and to develop novel drugs, researchers have taken advantage of motor neurons derived from disease-specific hiPSCs for pathological analysis [2-4]. However, the methods reported for motor neuron derivation from hPSCs in previous studies are time-consuming and require complicated manipulations. Moreover, the efficiency of these methods tends to be low, and show variability depending on hPSC clones referred to as clonal variations [5].

In this study, we established a simple, rapid, and reproducible method for efficiently deriving motor neurons from hPSCs without the transduction of any exogenous genes. This method facilitates simple and accurate pathophysiological analysis of motor neuron diseases using disease-specific hiPSCs.

\section{Results}

\section{Rapid and efficient motor neuron differentiation from} human pluripotent stem cells

By modifying our previously established method for deriving neural stem/progenitor cells (NS/PCs) as neurospheres from hPSCs through embryoid body (EB) formation [6,7], we established a rapid neural differentiation protocol from hPSCs (Fig. 1a). Because the derivation of NS/PCs from EBs using the previously established method takes 1 month, we first utilized dual SMAD inhibition to facilitate the neural differentiation of EBs [8]. KhES1 human embryonic stem cells [9] were detached from the feeder layer en bloc and cultured in suspension to form EBs using a BMP inhibitor $(3 \mu \mathrm{M}$ dorsomorphin) and a TGF $\beta$ inhibitor (3 $\mu \mathrm{M}$ SB4315342) during the first three days of differentiation (DS) (from day 1 to day 4). Although this dual SMAD inhibition slightly increased the expression of neural markers (PAX6 and SOX1) compared with untreated control cells, it was not sufficient to derive neural progenitors from EBs within two weeks of differentiation (Fig. 1b). Thus, to further facilitate neural differentiation, we added the GSK3 $\beta$ inhibitor ( $3 \mu \mathrm{M}\left(2^{\prime} \mathrm{Z}, 3^{\prime} \mathrm{E}\right)$-6-bromoindirubin-3'-oxime (BIO)) during the same period, in addition to dual SMAD inhibition (DSB). As a result, on day 8, the expression of PAX6 and SOX1 was significantly increased compared with control cells, by $3.7 \pm$ 0.4 -fold and $138 \pm 34$-fold, respectively (Fig. 1b). Moreover, the expression of the proneural gene NGN2 was increased by $68 \pm 16$-fold after 14 days of differentiation compared with untreated control cells. These results suggest that GSK3 $\beta$ inhibition has a positive effect on the neural differentiation of hESCs in our differentiation system, possibly by activating the canonical Wnt pathway through $\beta$-catenin. To drive differentiation into motor neurons, we added retinoic acid (RA) (from day 2 of EB formation) and purmorphamine, which activates the sonic hedgehog $(\mathrm{SHH})$ signaling pathway (from day 4 of EB formation), to confer caudal and ventral regional identities, respectively, upon hESC-derived NS/PCs. On day 14 of differentiation, the EBs expressed not only markers for the neural progenitors PAX6 and SOX1 but also additional transcription factors expressed in motor neuron progenitors, including OLIG2 and NGN2 (Fig. 1c). Subsequently, the EBs were dissociated into single cells and were adherently differentiated into neurons via monolayer culture in motor neuron medium (MNM). Within 1 week of adherent differentiation, $H B 9$ and ISL-1, markers for somatic motor neurons, were significantly upregulated (Fig. 1c). Consistent with these results, immunocytochemical analysis revealed the efficient induction of $\mathrm{HB}^{+} / \mathrm{ISL}^{-}{ }^{+} / \beta \mathrm{HII}-\mathrm{Tubulin}^{+}$motor neurons on day 7 of monolayer differentiation (HB9, $49.1 \pm 3.3 \%$, ISL-1, $47.9 \pm 2.0 \%, n=3$, Fig. $1 \mathrm{~d}$, e). Thus, we have established a rapid, efficient, and simple culture protocol that achieves motor neuron differentiation in only 2 weeks.

\section{Effects of long-term hESC-derived motor neuron culture in vitro}

To investigate the effects of the long-term culture of hESC-derived motor neurons, we examined temporal alterations of the expression of several motor neuron markers during 4 weeks of monolayer differentiation in MNM. Based on immunocytochemical analysis, the proportion of $\mathrm{HB}^{+}$and $\mathrm{ISL}-1^{+}$cells did not change greatly and consistently comprised approximately $50-60 \%$ of the total cells (Fig. 2a, b). By contrast, the proportion of cells positive for ChAT, a marker of mature motor neurons, was $54.6 \pm 4.5 \%$ at the end of one week and increased to $68.1 \pm 4.1 \%$ by 4 weeks of monolayer differentiation. Moreover, after 4 weeks of monolayer differentiation, the somas of the motor neurons had grown larger and were stained more clearly for ChAT 


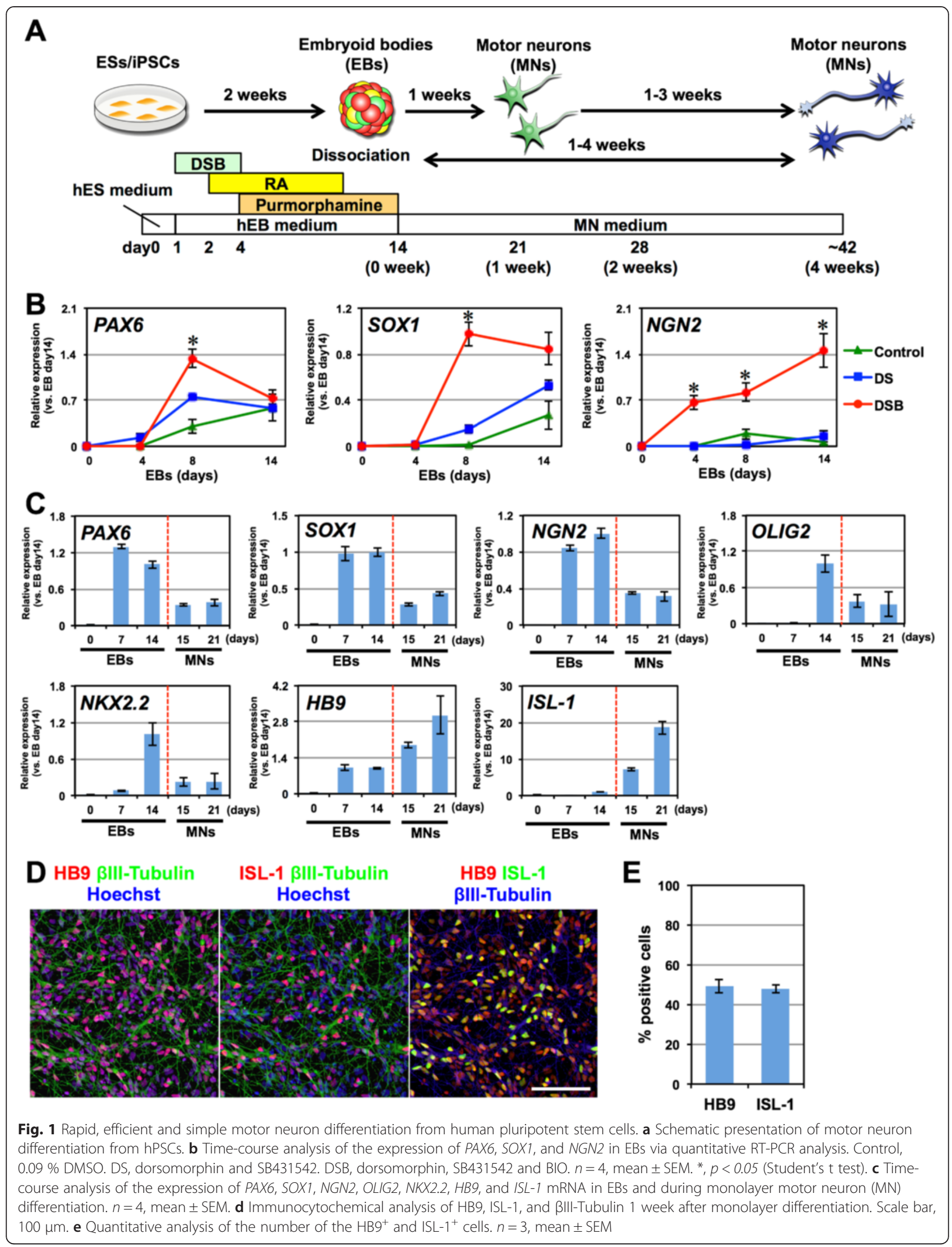




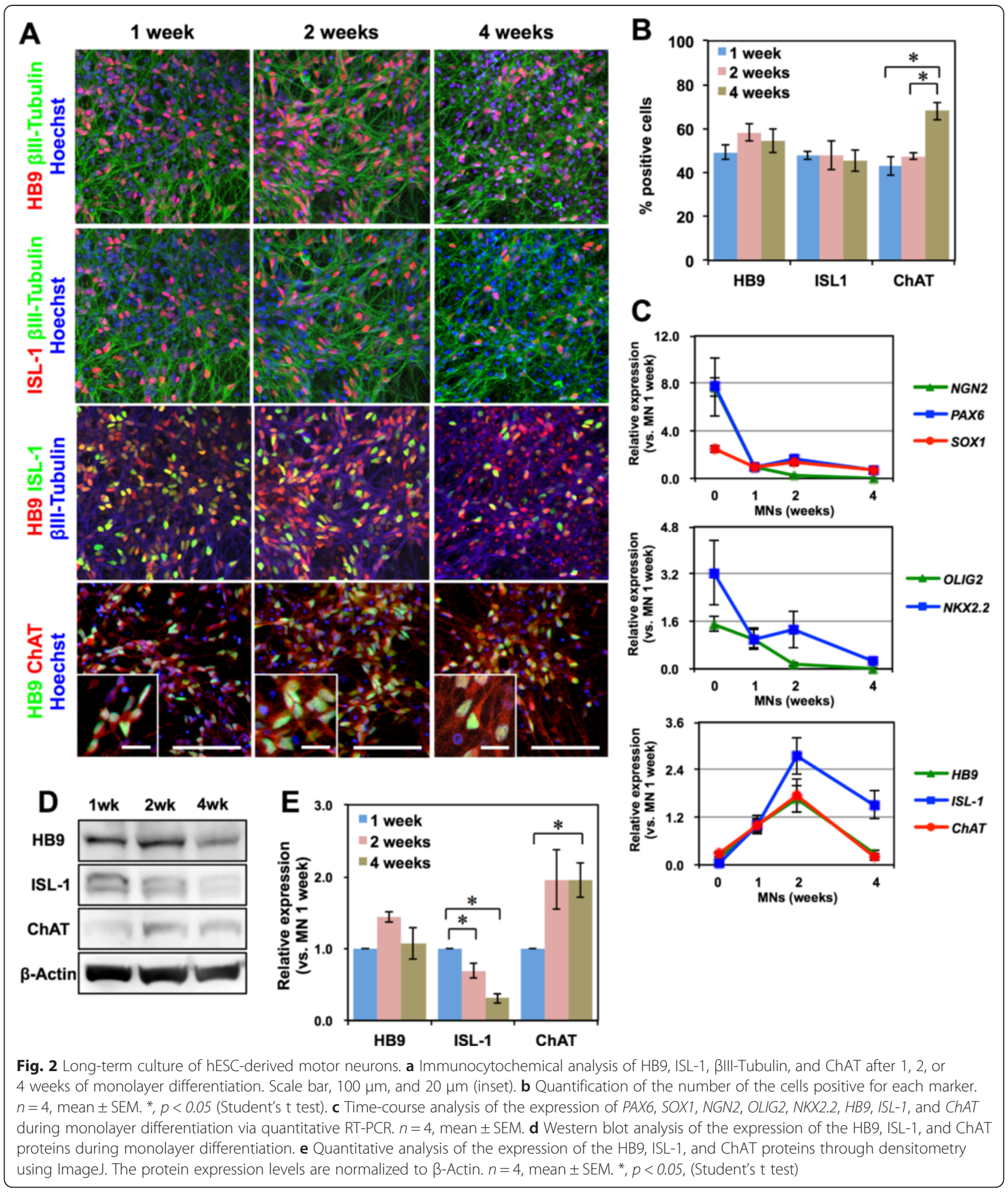

compared with those observed after 1 week of monolayer differentiation (Fig. 2a, insets). Quantitative RTPCR analysis revealed that the expression of genes known to be expressed in neural progenitor cells (PAX6, SOX1, NGN2, OLIG2, and NKX2.2) decreased during
4 weeks of monolayer differentiation, whereas markers of motor neurons (HB9, ISL-1, and ChAT) were increased during the first 2 weeks of differentiation, followed by a gradual decrease during the subsequent 2 weeks (Fig. 2c). To address the discrepancy in the time 
course of motor neuron marker expression between the immunocytochemistry and quantitative RT-PCR analyses, we also performed a western blot analysis (Fig. 2d, e). We found that the expression of the ChAT protein significantly increased during 4 weeks of differentiation, whereas the HB9 protein level was not significantly altered during this period (Fig. 2e). The ISL-1 protein was significantly decreased during monolayer differentiation as observed in the quantitative RT-PCR analysis (Fig. 2c). These results suggest that the expression of HB9 and ChAT might be regulated post-transcriptionally during the culture of hESC-derived motor neurons and that 4 weeks of monolayer differentiation facilitates the maturation of hESC-derived motor neurons.

\section{Co-culture with myotubes and the formation of neuromuscular junctions}

To examine the functional properties of hESC-derived motor neurons, we co-cultured hESC-derived motor neurons with skeletal muscle myotubes derived from the human myoblast cell line Hu5/E18 [10, 11]. KhES1-derived EBs containing motor neuron progenitors were partially dissociated and plated onto human myotubes differentiated from Hu5/E18 in MNM for 3-4 days. hESC-derived motor neurons labeled with $\beta$ III-Tubulin contacted myotubes, formed end plate-like structures, and induced clustering of acetylcholine receptors, which was visualized using Alexa 555-conjugated $\alpha$-Bungarotoxin (Alexa 555$\alpha$-BTX) (Fig. 3a, b). These results suggest that motor neurons derived in our system are competent to form functional neuromuscular junctions (NMJs) in vitro.

\section{Differentiation of hiPSCs into motor neurons}

We further examined whether this motor neuron differentiation system is applicable to hiPSCs. Three hiPSC clones (201B7, TIGE-9, and YFE-16) were differentiated into motor neurons following the same protocol (Fig. 4). 201B7 was kindly provided by Dr. Yamanaka [1], and TIGE-9 and YFE-16 were established in our laboratory from fibroblasts from adult males (36 and 24 years of age, respectively) by introducing OCT4, SOX2, KLF4, L$M Y C, L I N 28$, and shTP53 via episomal vectors; the last two clones were subjected to analysis of pluripotent marker expression via immunocytochemistry and quantitative RT-PCR, silencing of episomal transgenes, karyotype analysis, and teratoma formation capacity testing (Additional file 1: Figure S1). All of these clones efficiently differentiated into $\mathrm{HB}^{+}$and $\mathrm{ISL}^{-} 1^{+}$motor neurons that expressed the mature motor neuron marker ChAT by 4 weeks of monolayer differentiation (Fig. 4a). The proportions of $\mathrm{HB9}^{+}$and $\mathrm{ISL}-1^{+}$cells 1 week after monolayer differentiation of dissociated EBs derived from the three hiPSC clones were similar to those obtained from KhES1 hESCs, at approximately 40-50\%
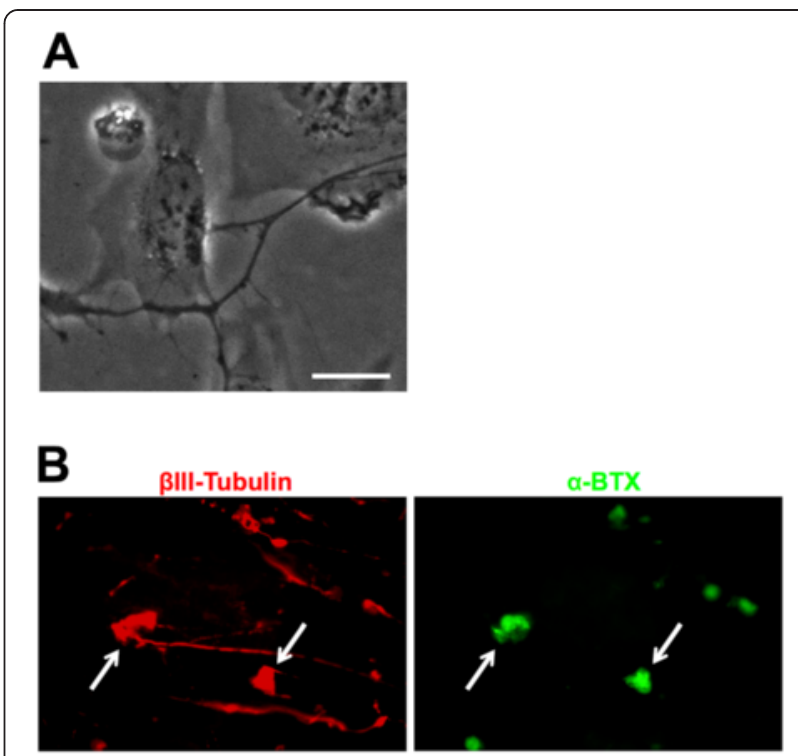

BIII-Tubulin $\alpha-B T X$ MyHC

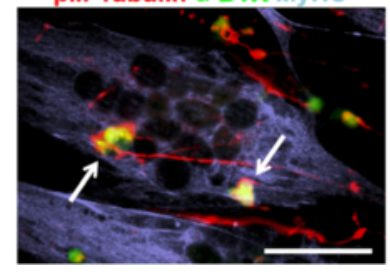

Fig. 3 Co-culture of hESC-derived motor neurons with myotubes. a Motor neurons derived from KhES1 cells were plated on myotubes derived from the human myoblast cell line Hu5/E18 to form end platelike structures. Scale bar, $20 \mu \mathrm{m}$. b Immunocytochemical analysis of $\beta I I I-T u b u l i n$ and $\mathrm{MyHC}$ after 3 days of co-culture with motor neurons and myotubes. AChR clusters were visualized with Alexa 555conjugated a-Bungarotoxin (a-BTX, white allows). Scale bar, $50 \mu \mathrm{m}$

(Fig. 4b). We also examined the time course of motor neuron marker expression via quantitative RT-PCR and western blotting and confirmed similar expression profiles in all of the hiPSC clones to those observed in KhES1 cells (Fig. 4c-e). These results suggest that our differentiation protocol is applicable to hiPSCs, thereby minimizing clonal variation among the hPSC clones.

\section{Replacement of small-molecule compounds by more specific and less toxic inhibitors}

Although our differentiation protocol achieved rapid and efficient differentiation of motor neurons from hPSCs, we observed significant cell death during EB formation after the addition of 3 compounds (DSB), which may have been caused by the cytotoxicity of the smallmolecule compounds (Fig. 5a). To avoid this massive cell death and more efficiently obtain motor neuron progenitors for further analysis, we examined the effects of other compounds that inhibit BMP and GSK3 $\beta$ on the differentiation of 201B7 iPSCs. We first replaced BIO with CHIR99021, a more specific and less toxic inhibitor 


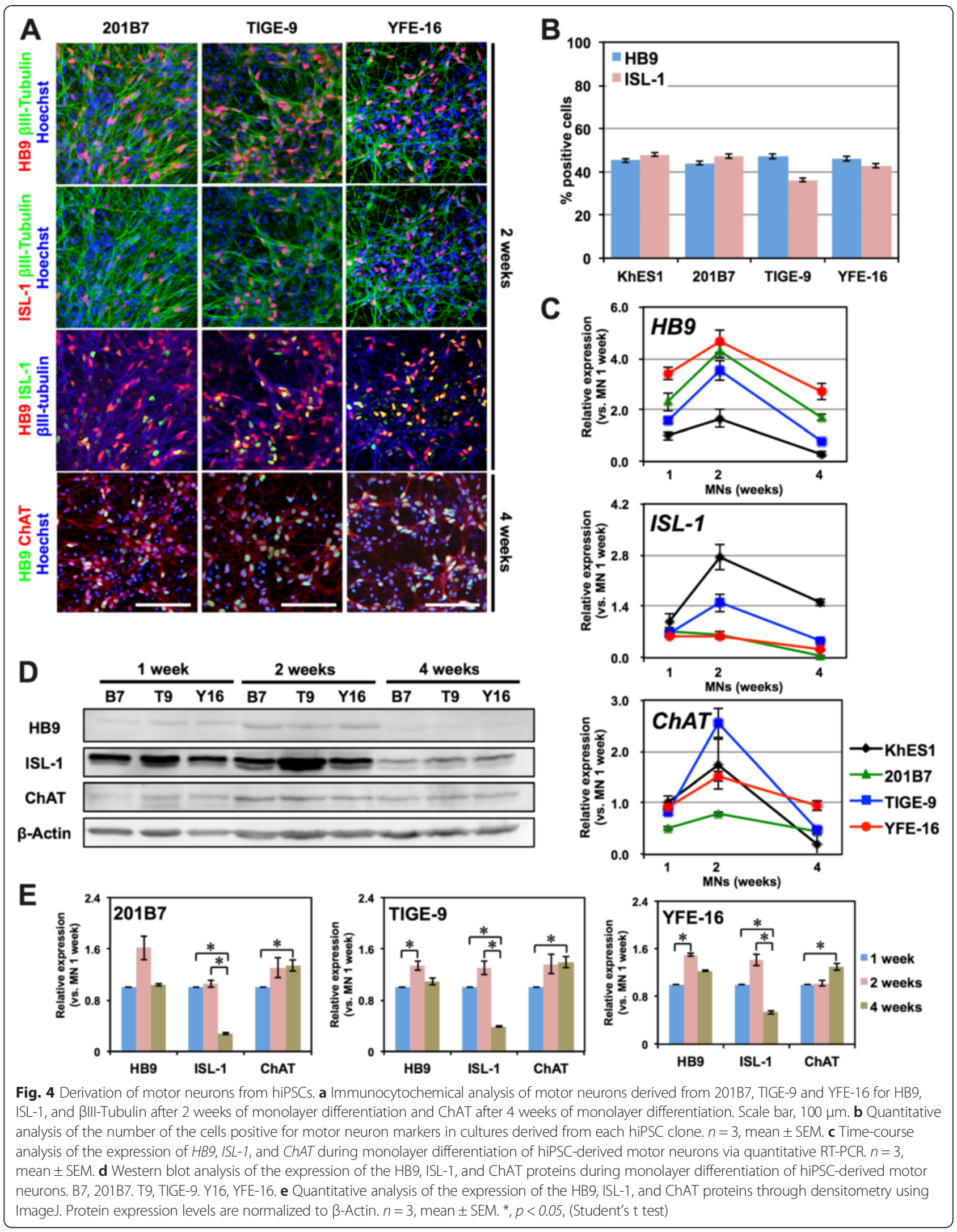




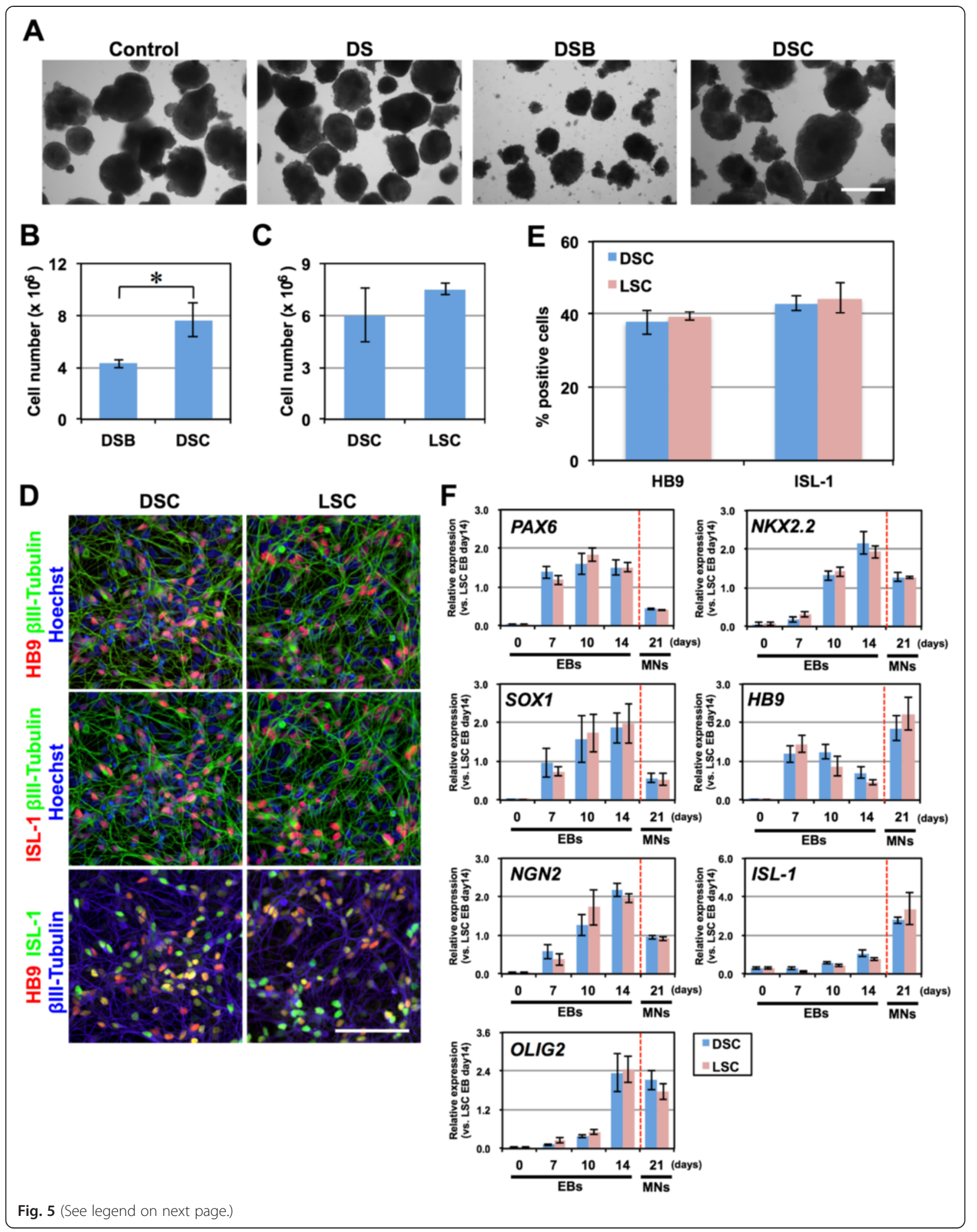


(See figure on previous page.)

Fig. 5 Replacement of small molecule compounds with more specific and less toxic inhibitors. a Morphology of EBs, which were derived from 201B7, treated with vehicle (DMSO), DS, DSB, or DSC on day 4. Massive cell death was observed after the treatment of DSB. Scale bar = 200 $\mu$ m. Control, 0.09 \% DMSO. DS, dorsomorphin and SB431542. DSB, dorsomorphin, SB431542, and BIO. DSC, dorsomorphin, SB431542, and CHIR99021. b The number of cells harvested from DSB- and DSC-treated EBs on day 14 per 100-mm culture dish of starting hiPSCs. $n=4$, mean \pm SEM. * $p<0.05$ (Student's t test). c The number of cells harvested from DSC-and LSC-treated EBs on day 14 per 100-mm culture dish of starting hiPSCs. $n=4$, mean \pm SEM. LSC, LDN193189, SB431542, and CHIR99021. d Immunocytochemical analysis of motor neurons derived from DSC- or LSCtreated EBs for HB9, ISL-1 and BIII-Tubulin on day 7 of monolayer differentiation. Scale bar, $100 \mu \mathrm{m}$. $\mathbf{d}$ Quantitative analysis of the number of the cells positive for HB9 and ISL-1. $n=4$, mean \pm SEM. e Time-course analysis of the expression of PAX6, SOX1, NGN2, OLIG2, NKX2.2, HB9, and ISL-1 in EBs and during monolayer differentiation of motor neurons (MN) via quantitative RT-PCR. $n=4$, mean \pm SEM

of GSK3 $\beta$ [12], and observed a significant reduction in cell death during EB formation (Fig. 5a). Treatment of EBs with CHIR99021 in combination with DS (DSC) resulted in a $1.79 \pm 0.50$-fold increase in the cell number obtained from EBs after 14 days of differentiation compared with those treated with DSB (Fig. 5b). We also examined the effects of LDN193189, a more specific and less toxic inhibitor of BMP signals [13]. When EBs were treated with LDN193189, SB4315342, and CHIR99021 (LSC), we observed a $1.54 \pm 0.43$-fold increase in the number of cells obtained from EBs after 14 days of differentiation compared with those treated with DSC, but the difference was not statistically significant (Fig. 5c). No significant differences in the differentiation of motor neurons were observed among the populations subjected to the DSB, DSC, and LSC treatments. The proportions of $\mathrm{HB}^{+}$motor neurons under DSC and LSC conditions were $37.9 \pm 3.4$ and $39.4 \pm 1.1 \%$, respectively (Fig. $5 \mathrm{~d}$, e), and the results of time-course analysis of the expression of motor neuron markers did not differ significantly among the DSB, DSC, and LSC treatments (Fig. 4a, b and $5 \mathrm{~d}, \mathrm{e})$. Together, these results suggest that both the DSC and LSC protocols are useful in practice for obtaining a greater number of motor neuron progenitors and that the inhibition of BMP and TGF $\beta$ signals combined with inhibition of GSK3 $\beta$, which activates canonical WNT signaling, have positive effects on the induction of neural progenitors, excluding the off-target effects of these compounds.

\section{Visualization of motor neurons using an $H B 9^{\mathrm{e}}{ }^{438}$ ::Venus reporter lentivirus}

Although our method achieved efficient motor neuron derivation, the proportion of $\mathrm{HB}^{+}$motor neurons was approximately 40-50\%, and other cell types persisted in culture, presenting an obstacle for the analysis of motor neuron-specific biological events. To address these issues, we constructed an $H B 9^{e 438}:$ :Venus reporter lentivirus, in which the Venus fluorescent protein (an altered yellow fluorescent protein; [14]) is expressed under the control of the 438-base pair $H B 9$ enhancer element $\left(H B 9^{e 438}\right.$, [15]) and the human $\beta$-globin minimal promoter. After 3-4 days of monolayer differentiation, KhES1-derived motor neurons were infected with the
$H B 9^{e 438}::$ Venus reporter lentivirus and were observed to extend Venus $^{+}$neurites $24 \mathrm{~h}$ after lentivirus infection (Fig. 6a). At one, two, or four weeks after lentivirus infection, cells were fixed and subjected to immunocytochemistry to detect HB9 and Venus (using an anti-GFP antibody) (Fig. 6b). Most Venus ${ }^{+}$cells were also positive for HB9 one week after lentiviral infection (HB9/ Venus $=84.1 \pm 2.4 \%$, Fig. 6c), suggesting that the expression of the Venus fluorescent protein accurately reflects HB9 expression. Many cells were also positive for another motor neuron marker, ISL-1, after 1 week (ISL-1/Venus $=39.5 \pm 13.2 \%$, Fig. 6c). Moreover, after 4 weeks of monolayer differentiation, most Venus $^{+}$cells were also positive for ChAT (ChAT/Venus $=83.4 \pm 1.7 \%$, Fig. 6c). These results suggest that the HB9 ${ }^{e 438}:$ :Venus lentivirus reporter allows accurate visualization of live motor neurons derived from hPSCs.

To further confirm the relevance of this reporter, we examined the expression of the $H B 9^{e 438}::$ Venus lentivirus through fluorescence-activated cell sorting (FACS) one week after the infection of 201B7-derived motor neurons. We divided the cells into 4 fractions: a negative fraction (gated by the fluorescence intensity of uninfected controls, gray peak) and 3 positive fractions (green peak), where the positive cells were equally subdivided into low-positive, middle-positive, and highpositive fractions (Fig. 6d). The cells in each of the 4 fractions were sorted and subjected to quantitative RTPCR analysis to detect the expression of Venus mRNA and the motor neuron markers HB9, ISL-1, and ChAT (Fig. 6e). We observed a significant increase in the expression of Venus, $H B$ 9, and $I S L-1$ in the high-positive fraction ( $p<0.05$, Kruskal-Wallis test) and a tendency for the expression of ChAT to increase. The expression levels of $H B 9$ and $I S L-1$ in the high-positive fraction were $12.4 \pm 5.4$-fold and $6.4 \pm 2.6$-fold higher than in the negative fraction. We also examined the expression of Venus fluorescent protein from a reporter lentivirus containing the same vector backbone, but without the $H B 9^{e 438}$ enhancer element (background reporter lentivirus; Yellow peak in Fig. 6d), and found that the fluorescence observed in the high-positive fraction of $H B 9^{e 438}::$ Venus reporter-transduced cells overlapped minimally with the fluorescence generated by the 


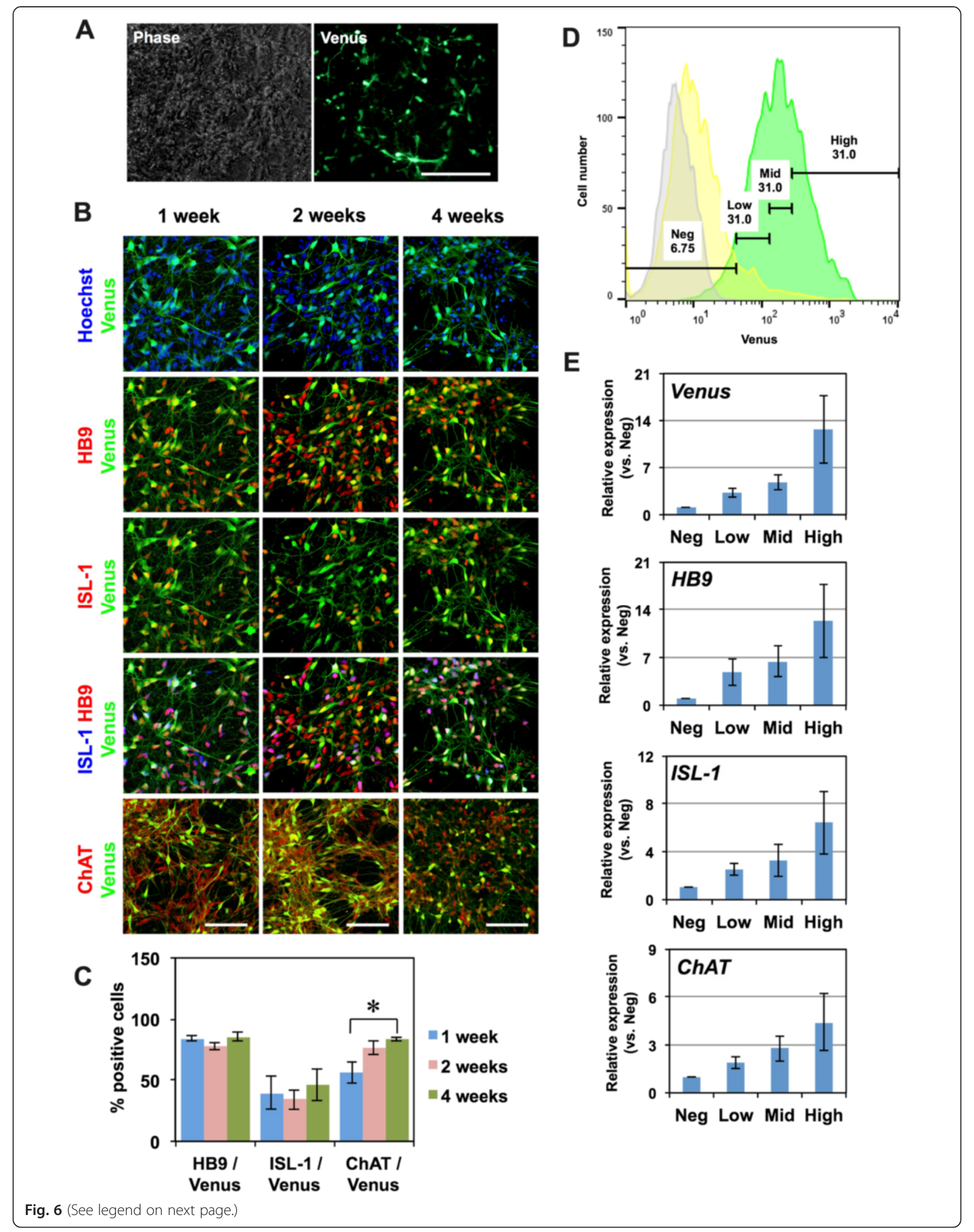


(See figure on previous page.)

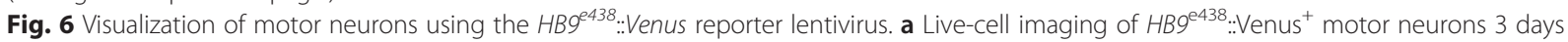
after lentivirus infection. Scale bar, $100 \mu \mathrm{m}$. b Immunocytochemical analysis of motor neurons for HB9, ISL-1, ChAT, and Venus (GFP antibody) at 1, 2, and 4 weeks after $H B 9^{e 438}:$ :Venus lentivirus infection. Scale bar, $100 \mu \mathrm{m}$. c Quantitative analysis of the number of cells positive for HB9, ISL-1, and ChAT among Venus ${ }^{+}$cells. $n=4$, mean \pm SEM.*,$p<0.05$ (Student's t test) $\mathbf{d}$ Histograms of HB9 ${ }^{483}: .:$ Venus lentivirus-infected cells (Green), background lentivirus ( $\beta$-glo::Venus)-infected cells (Yellow), and uninfected control cells (Gray) via flow cytometry. The $\mathrm{HB}^{2438}{ }^{2: V e n u s}{ }^{+}$cells were divided into 4 fractions: a negative fraction ( $\mathrm{Neg}$ ), in which the fluorescence intensities were equivalent to an uninfected negative control, and a low-positive fraction (Low), a middle-positive fraction (Middle), and a high-positive fraction (High), in which the fluorescence intensities were equivalent to the lowest $1 / 3$, the next lowest $1 / 3$, and the highest $1 / 3$ of fluorescence intensities within the positive fraction, respectively. e The expression of Venus, ISL-1, HB9, and ChAT in each fraction determined via quantitative RT-PCR. $n=3$, mean \pm SEM. A significant increase in the expression of Venus, HB9, and ISL-1 in the high-positive fraction was observed ( $p<0.05$, Kruskal-Wallis test)

background reporter. Together, these results suggested that the high-positive fraction was a bona fide "motor neuron fraction" and that this approach can be used for the purification of hPSC-derived motor neurons.

\section{Discussion}

Rapid and efficient motor neuron induction from hiPSCs In this report, we have demonstrated a protocol for effective and reproducible motor neuron derivation that does not require transgene expression. Although hESCs and hiPSCs have been differentiated into $\mathrm{HB9}^{+}$, ISL- $1^{+}$, and $\mathrm{ChAT}^{+}$motor neurons in several previous studies, our method of motor neuron derivation is superior for the following three reasons: 1) its short culture period and simple culture method; 2) the high purity of the $\mathrm{HB}^{+}$motor neurons obtained; and 3) its reproducibility among several hPSC lines, thereby minimizing clonal variation. One previously reported method for deriving motor neurons from hPSCs is based on the serum-free floating culture of EB-like aggregates with quick reaggregation (SFEBq) method $[2,16]$. Although this method is widely known, it requires 35 days, and the procedure is complicated. Moreover, while the purity of SMI- $32^{+}$ motor neurons derived from $201 \mathrm{~B} 7$ iPSCs was $35 \%$, the purity of other iPSC clones was only 15-30\%, with significant variability. Several methods have been established in previous studies to improve the efficiency of motor neuron derivation. For example, a method involving dual SMAD inhibition, using dorsomorphin and SB431542, enabled the production of over $50 \%$ pure $\mathrm{HB}^{+}$motor neurons, but induction of these motor neurons required approximately 30 days $[17,18]$. In other studies, motor neurons were induced within 20-25 days, but the purity of $\mathrm{HB}^{+}$cells was only $20-30 \%[19,20]$. In the present study, we derived $40-50 \%$ pure $\mathrm{HB}^{+}$ motor neurons within 2 weeks, achieving a high efficiency within a short culture period. In addition, the efficiency of motor neuron derivation was consistently 40-50 \% among several hPSC clones. Therefore, we have overcome the issue of clonal variation among hiPSC clones [5] and established a more stable in vitro model for the pathophysiological analysis of motor neuron diseases.

\section{GSK3 $\beta$ inhibitor treatment enhances neural induction}

In this study, rapid and efficient neural induction was achieved by treating cells with BIO or CHIR99021 in addition to dual SMAD inhibition at an early stage of differentiation. GSK3 $\beta$ inhibitors such as BIO and CHIR99021 have recently been used for neural induction $[3,18,21]$. However, the effects of GSK3 $\beta$ inhibitors have not been discussed in detail. We examined the difference in gene expression following "DS" and "DSB" treatments and found that PAX6, SOX1, and NGN2 were upregulated by BIO. $\beta$-catenin, which is stabilized by the GSK3 $\beta$ inhibitor BIO, is reported to form a complex with TCF1 and to directly promote the transcription of PAX6, SOX1, and NGN2 [22]. In addition, $\beta$-catenin is known to form a complex with the intracellular domain of Notch and enhances HES1 expression, which in turn promotes the proliferation of NS/PCs and inhibits the differentiation of NS/PCs [23]. Thus, the activation of Wnt $/ \beta$-catenin signaling by GSK3 $\beta$ inhibition may directly enhance the transcription of genes associated with the initial steps of neural induction and may also promote the proliferation of induced NS/PCs in our culture system.

\section{Effect of long-term monolayer culture on the maturation of motor neurons}

Cell maturation is particularly important in pathological models of late-onset disease because the cells derived from hPSCs are often immature and do not recapitulate disease phenotypes. In one previous report, more than 100 days of monolayer differentiation were required to detect an apparent phenotype in neurons derived from disease-specific hiPSCs [24]. To recapitulate aging in iPSC-derived neurons, forced expression of Progerin, which is known to enhance cellular aging, was performed to detect the phenotypes of the diseased neurons [25]. Moreover, the recapitulation of cellular stress in vivo using glutamate or endoplasmic reticulum (ER) stress driven by tunicamycin has been employed to examine the pathology of neurons or glial cells derived from disease-specific hiPSCs [26, 27]. By contrast, a detailed time-course analysis of gene expression during motor neuron differentiation and the relationship 
between the length of the culture period and the maturation of motor neurons remains to be reported. We found that the expression of the ChAT protein was upregulated, and the soma of motor neurons became larger and was more clearly stained for ChAT over the course of four weeks of monolayer differentiation, suggesting that motor neurons matured over this time in vitro [28]. Thus, a 4 week period of monolayer differentiation is required for the maturation of hPSC-derived motor neurons. Further improvements of culture conditions for maturing motor neurons are expected in future studies.

In this study, we found that HB9 and ChAT protein were unchanged or upregulated, though HB9 mRNA and ChAT mRNA was decreased after 2 weeks of monolayer differentiation. This discrepancy may be attributable to post-transcriptional regulations of these genes during the maturation of motor neurons. In the process of neural differentiation, post-transcriptional regulations are known to play important roles to determine cell fates or behaviors. For instance, ubiquitin specific protease 7 (USP7) deubiquitinates RE1-silencing transcription factor (REST) protein and maintain its protein expression to keep stemness of NS/PCs [29]. For another example, the translation of FoxP1 in motor neuron progenitors in chick is suppressed by miR-9 and promotes their differentiation into the neurons in medium motor columns via the increase of Hb9 and Lhx3 and the decrease of Isl-1 [30]. In the developing human neocortex, the translation of Nitric oxide synthase 1 (NOS1) mRNA is temporally and regionally regulated by the expression of Fragile $\mathrm{X}$ mental retardation protein (FMRP), which is expressed only in pyramidal neurons during early synaptogenesis, though NOS1 mRNA is widely expressed [31]. Moreover, in the axonal terminal of mature neurons, the expression of Deleted in colorectal carcinoma (DCC) proteins depends on the regulation of local translation to quickly respond to exogenous signals [32]. Considering these region- and stage-specific post-transcriptional regulations, the mismatch between mRNA and protein expression of HB9 and ChAT in the present study may be attributable to such post-transcriptional regulations, which may have important roles in the differentiation or the maturation of PSC-derived motor neurons.

In contrast to the sustained expressions of HB9 and ChAT proteins, both $I S L-1$ mRNA and ISL- 1 protein were significantly decreased after 2 weeks of monolayer differentiation, but the number of $\mathrm{ISL}_{-} 1^{+}$cells was not significantly decreased (Fig. 2b). Considering the reproducibility of these results in several hPSC clones, KhES1, 201B7, TIGE-9, and YFE-16 (Figs. 2e, 4e), these results suggest that the expression of ISL-1 per motor neurons decreases as the maturation progressed. Because precise expression of ISL-1 during the maturation of motor neurons has never been discussed in detail so far, the regulation and the biological significance of the expression of ISL-1 should be clarified in the future.

The $H B 9^{e 438}$ ::Venus reporter lentivirus is a useful fluorescent probe for visualizing and purifying $\mathrm{HB}^{+}$motor neurons hPSC-derived motor neurons are usually mixed with non-motor neurons following differentiation. They must therefore be identified and purified prior to the examination of motor neuron-specific pathogenesis. For the analysis of multiple hiPSC clones for the purpose of reproducibility, direct labeling of hPSC-derived motor neurons by a lentiviral reporter is an easy and efficient method. In an initial report, $9 \mathrm{~kb}$ of the $5^{\prime}$ upstream region of the $H B 9$ gene, including the $H B 9$ enhancer/promoter element, was identified and has since been widely used to visualize $\mathrm{HB}^{+}$motor neurons [33]. Subsequently, it was determined that the $5^{\prime} 3.6 \mathrm{~kb}$ fragment of this $9 \mathrm{~kb}$ element is necessary and sufficient for the transcription of $H B 9$ in mice, especially the 438-bp or 125-bp enhancer elements containing $\mathrm{Pdx}$ and Hox binding domains [15]. Therefore, to construct an efficient reporter system for $H B 9$, we generated a reporter lentivirus that expresses the Venus fluorescent protein under the control of the 438-bp HB9 enhancer element and the $\beta$-globin minimal promoter (HB9 $9^{e 438}:$ :Venus), which has been shown to specifically label hPSC-derived $\mathrm{HB}^{+}$motor neurons with more than $80 \%$ accuracy via immunocytochemistry (Fig. 6c). Although this reporter system exhibits some background signal, possibly due to the background activity of the $\beta$-globin minimal promoter, gating our analysis to the high-positive fraction, consisting of the top $1 / 3$ fraction of HB9::Venus ${ }^{+}$cells, enabled us to obtain bona fide $\mathrm{HB}^{+}$motor neurons (Fig. 6d). Thus, this reporter system allows accurate visualization and purification of hPSC-derived motor neurons and permits us to perform motor neuronspecific analysis, yielding a powerful tool for the pathophysiological analysis of disease-specific motor neurons.

\section{Conclusions}

We established a rapid, efficient and simple method for motor neuron differentiation from hPSCs. We also visualized motor neurons using an HB9 reporter lentivirus (HB9 $9^{e 438}::$ Venus). These techniques can be applied to the effective pathophysiological analysis of motor neuron diseases using disease-specific iPSCs.

\section{Materials and methods}

\section{Isolation of human skin fibroblasts and generation of} hiPSCs

Human dermal fibroblasts (HDFs) were obtained from a 24-year-old Japanese male via skin punch biopsy (YFHDF) and from a 36-year-old Japanese male from the Japanese Collection of Research Bioresources (JCRB) 
Cell Bank (TIG114-HDF). HDFs were cultured in DMEM (Sigma-Aldrich, St Louis, MO, USA), $10 \%$ fetal bovine serum (FBS; Sigma-Aldrich, St Louis, MO, USA), $2 \mathrm{mM}$ L-glutamine, and $1 \%$ penicillin/streptomycin. Then, $6 \times 10^{5}$ HDFs were transfected with $1 \mu \mathrm{g}$ of each of pCXLE-hOCT3/4-shp53 (OCT4 and shTP53), pCXLEhSK (SOX2 and KLF4) and pCXLE-hUL (L-MYC and LIN28; a gift from Dr. Yamanaka) [34]. Plasmid transfection was performed using the Neon transfection system (Thermo Fisher Scientific, USA). After 6 days, the cells were harvested and plated on mitomycin-C-treated SNL murine fibroblast feeder cells in $0.1 \%$ gelatin-coated tissue culture dishes in human fibroblast medium. On the next day, the medium was changed to standard hESC medium containing DMEM/F-12 (Wako, Japan), 20 \% knock out serum replacement (KSR) (Thermo Fisher Scientific, USA), 2 mM L-glutamine, $1 \%$ non-essential amino acids (NEAA) (SigmaAldrich, USA), $0.1 \mathrm{mM}$ 2-melchaptethanol (2-ME) (SigmaAldrich, USA), $0.5 \%$ penicillin/streptomycin and $4 \mathrm{ng} / \mathrm{mL}$ recombinant human fibroblast growth factor-2 (FGF-2) (Peprotech, USA). When the colonies were sufficiently large in size, they were picked and expanded in the same way as hESCs. The properties of the established hiPSC clones were evaluated as described previously (Additional file 1: Figure S1) [34]. hiPSC clones YFE-16 and TIGE-9 were established from YF-HDF and TIG114-HDF, respectively.

All of the experimental procedures for hiPSC production were approved by the ethics committee of the Keio University School of Medicine (approval number 20080016) and the ethics committee of the Aichi Medical University School of Medicine (approval number 14-004). All of the experimental procedures for human embryonic stem cell culture were approved by the ethics committee of the Keio University School of Medicine (approval number 2002-001).

\section{hESC and hiPSC culture and differentiation in vitro}

KhES1 (a gift from Dr. Norio Nakatsuji) [9], $201 \mathrm{~B} 7$ (a gift from Dr. Shinya Yamanaka) [1], TIGE-9, and YFE-16 cells were maintained on mitomycin-C-treated SNL murine fibroblast feeder cells or mouse embryonic fibroblasts (MEFs) in $0.1 \%$ gelatin-coated tissue culture dishes in hESC medium and were used for motor neuron induction. For differentiation, hESC/hiPSC colonies were detached using a dissociation solution containing $0.25 \%$ trypsin, $100 \mu \mathrm{g} / \mathrm{ml}$ collagenase IV (Invitrogen, 17104-019), $1 \mathrm{mM}$ $\mathrm{CaCl}_{2}$, and $20 \% \mathrm{KSR}$ and cultured in suspension in bacteriological dishes in standard hESC medium without FGF2 , after the removal of SNL feeder cells, with incubation for 1-2 $\mathrm{h}$ in gelatin-coated dishes. On day 1 , the medium was changed to human embryoid body (hEB) medium containing DMEM/F-12, 5 \% KSR, 2 mM L-glutamine, $1 \%$ NEAA, and $0.1 \mathrm{mM} 2-\mathrm{ME}$ with $3 \mu \mathrm{M}$ dorsomorphin dihydrochloride (Santa Cruz, USA), $3 \mu$ M SB431542 (Santa
Cruz, USA), and $3 \mu \mathrm{M}$ BIO (Sigma-Aldrich, USA). On day 2 , the medium was changed to new hEB medium containing $3 \mu \mathrm{M}$ dorsomorphin dihydrochloride, $3 \mu \mathrm{M}$ SB431542, $3 \mu \mathrm{M} \mathrm{BIO}$, and $1 \mu \mathrm{M}$ retinoic acid (RA) (Sigma-Aldrich, USA). From day 4 to day 14 , hEBs were cultured in hEB medium containing $1 \mu \mathrm{M}$ RA and $1 \mu \mathrm{M}$ purmorphamine (Calbiochem, Germany), and the medium was changed every 2-3 days. On day 14, hEBs were enzymatically dissociated into single cells using TrypLE Select (Thermo Fisher Scientific, USA). The dissociated cells were plated on recombinant mouse Laminin (Thermo Fisher Scientific, USA)-coated dishes at a density of $5 \times 10^{4}-1 \times 10^{5}$ cells $/ \mathrm{cm}^{2}$ and cultured in motor neuron medium (MNM) consisting of media hormone mix (MHM) or KBM Neural Stem medium (Kohjin Bio, Japan) [6] supplemented with $2 \%$ B27 supplement (Thermo Fisher Scientific, USA), $1 \%$ NEAA, 50 nM RA, $500 \mathrm{nM}$ purmorphamine, $10 \mu \mathrm{M}$ cyclic AMP (cAMP) (Sigma-Aldrich, USA), $10 \mathrm{ng} / \mathrm{mL}$ recombinant BDNF (R\&D systems, USA), $10 \mathrm{ng} / \mathrm{mL}$ recombinant GDNF (R\&D systems, USA), $10 \mathrm{ng} / \mathrm{mL}$ recombinant human IGF-1 (R\&D systems, USA) and $200 \mathrm{ng} / \mathrm{mL}$ L-ascorbic acid (Sigma-Aldrich, USA) for 1, 2, or 4 weeks (i.e., 21, 28, or 42 days from EB formation). Half of the medium was changed every $2-3$ days.

\section{Generation of the $H B 9^{e 438}:$ :Venus lentivirus and visualization of $\mathrm{HB}^{+}$motor neurons}

HEK293T cells cultured in the Freestyle 293 expression medium (Thermo Fisher Scientific, USA) in $150 \mathrm{~mm}$ dishes

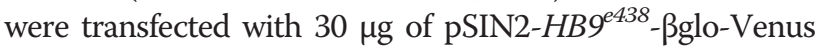
and $20 \mu \mathrm{g}$ of each of two packaging vectors (pCMV-VSV-G and pCAG-HIV-gp, kindly provided by Dr. Hiroyuki Miyoshi) in $280 \mu \mathrm{L}$ of Gene Juice (Novagen, USA), and the medium was changed the next day. Three days after the medium change, the culture supernatant was harvested and centrifuged at $25,000 \mathrm{rpm}$ for $90 \mathrm{~min}$ at $4{ }^{\circ} \mathrm{C}$ in an Optima LE-80 K ultracentrifuge (Beckman Coulter, USA). After discarding the supernatant, $80 \mu \mathrm{L}$ of $\mathrm{PBS} / 150 \mathrm{~mm}$ dish was added to the pellet, which was resuspended by repeated pipetting to obtain the $H B 9^{e 438}:$ :Venus reporter lentivirus.

Lentiviral infection was performed on day 3 or 4 of monolayer motor neuron differentiation. For lentiviral infection, $H B 9^{e 438}:$ :Venus in Opti-MEM (Thermo Fisher Scientific, USA) was added to a motor neuron culture, followed by incubation for $2 \mathrm{~h}$, after which the total medium was changed to MNM. The cells were cultured for 1, 2, or 4 weeks (i.e., 24, 31, or 45 days after EB formation) and used for subsequent analyses.

\section{Hu5/E18 culture, differentiation and co-culture with motor neurons}

The human myoblast cell line Hu5/E18 was cultured in collagen type I-coated 10-cm dishes (Iwaki, Japan) or Cellmatrix type I-P (Nitta gelatin, Japan) -coated dishes in 
myoblast medium containing DMEM, 20 \% FBS, 2 mM Lglutamine, $0.5 \%$ penicillin/streptomycin and $2 \%$ Ultroser $\mathrm{G}$ serum substitute (Pall, France). For in vitro neuromuscular co-culture, Hu5/E18 cells were plated at a density of $1 \times 10^{3}$ cells $/ \mathrm{ml}$ on a Cellmatrix type I-P-coated micro cover glass (Matsunami, Japan) and cultured until the cells reached approximately $50 \%$ confluence. Then, the medium was changed to MNM, and the cells were cultured for 4 additional days, until the formation of myotubes. Partially dissociated EBs derived from KhES1 cells were plated onto Hu5/E18-derived myotubes at a density of $2.5 \times 10^{2}-5 \times 10^{3}$ cells $/ \mathrm{cm}^{2}$ and cocultured with the myotubes for 3-4 days in MNM.

\section{RNA isolation and quantitative RT-PCR analysis}

RNA was isolated using an RNeasy mini kit (Qiagen, Germany) and then converted into cDNA using SuperScript III reverse transcriptase (Thermo Fisher Scientific, USA) and Oligo dT primers as described previously [35]. Quantitative RT-PCR analysis was performed using SYBR premix ex Taq II (Takara, Japan) and the Mx3000P (Stratagene, USA), Step One Plus, or ViiA7 real-time PCR system (Applied Biosystems, USA). The amount of cDNA was normalized to that of humanspecific $\beta$-ACTIN mRNA. The sequences of the primers and the corresponding cycling conditions are described in Table 1.

\section{Immunocytochemistry}

Cells were fixed in $4 \%$ paraformaldehyde for 15-25 min at room temperature. After blocking in blocking buffer (PBS containing 5 FBS and $0.3 \%$ Triton X-100), the cells were incubated with primary antibodies overnight at $4{ }^{\circ} \mathrm{C}$. The cells were then rinsed with PBS three times and incubated with Alexa 488-, Alexa 555-, or Alexa 647conjugated secondary antibodies (Thermo) for $1 \mathrm{~h}$ at room temperature. Nuclei were stained with $10 \mu \mathrm{g} / \mathrm{ml}$ Hoechst 33258 (Sigma-Aldrich, USA). The cells were then rinsed with PBS three times, mounted on slides and examined using a universal fluorescence microscope (Axiophoto, Carl Zeiss, Germany) or confocal laser-scanning microscope (LSM700, Carl Zeiss, Germany). The primary antibodies used in these analyses were as follows: HB9 (mouse $\operatorname{IgG}_{1}, 1: 200$, Developmental Studies Hybridoma Bank [DSHB], USA), ISL-1 (mouse $\operatorname{IgG}_{2 \mathrm{a}}, 1: 200$, DSHB, USA), $\beta$ III-Tubulin (mouse $\operatorname{IgG}_{2 \mathrm{~b}}, 1: 4000$, Sigma-Aldrich, USA or rabbit IgG, 1:4000, Biolegend, USA), ChAT (goat IgG, 1:200, Millipore, USA), GFP (rabbit IgG, 1:200, MBL, USA), and MyHC (mouse $\operatorname{IgG}_{2 \mathrm{~b}}, 1: 200$, DSHB, USA). For the observation of $\mathrm{n}$-AChR clusterization, Alexa fluor 555 -conjugated $\alpha$-Bungarotoxin, $(1 \mu \mathrm{g} / \mathrm{mL}$, Invitrogen, USA) was added to samples and incubated for $1 \mathrm{~h}$.

\section{Western blot analysis}

Western blot analysis was performed as previously reported. A protein sample from a total cell extract $(10 \mu \mathrm{g})$ was run

Table 1 Primer sequences and cycling conditions for quantitative RT-PCR analysis

\begin{tabular}{|c|c|c|c|c|c|c|c|}
\hline Gene & Sense & & Antisense & & $\begin{array}{l}\text { Product } \\
\text { size }\end{array}$ & Temp. & $\begin{array}{l}10 \% \\
\text { DMSO }\end{array}$ \\
\hline SOX1 & hSOC1-S3755 & GAAATAGCCAATGCCAGGTG & hSOX1-AS4039 & CCGTGAATACGATGAGTGTTACC & 285 & 62 & - \\
\hline PAX6 & hPAX6-S421 & TAGGGGCGCGCAGATGTGTG & hPAX6-AS538 & TGCATGCTGGCTCTGGCTGG & 118 & 68 & - \\
\hline OLIG2 & hOLIG2-S49 & GTTCTCCCCTGAGGCTTTTC & hOLIG2-AS223 & AGAAAAAGGTCATCGGGCTC & 175 & 67 & - \\
\hline NKX2.2 & hNKX2.2-S434 & GCTCTGTGGCCGAAGGTCCG & hNKX2.2-AS657 & GCTTGAGTCCTGAGGGGGCG & 224 & 62 & - \\
\hline ISL-1 & hISL1-S1294 & AGCAGCCCAATGACAAAACT & hISL1-AS1494 & CTGAAAAATTGACCAGTTGCTG & 201 & 60 & - \\
\hline HB9 & hHB9-S951 & GTCCACCGCGGGCATGATCC & hHB9-AS1162 & TCTTCACCTGGGTCTCGGTGAGC & 212 & 62 & - \\
\hline CHAT & hChAT-S1360 & GGAGGCGTGGAGCTCAGCGACACC & hChAT-AS1592 & CGGGGAGCTCGCTGACGGAGTCTG & 256 & 62 & - \\
\hline NGN2 & hNGN2-S93 & AGACACGCACCACCACCACAACAC & hNGN2-AS293 & TGACTITGGCCTGTGCCGGGAATC & 201 & 60 & + \\
\hline EBNA-1 tg & EBNA-1-S & ATCAGGGCCAAGACATAGAGATG & EBNA-1-AS & GCCAATGCAACTTGGACGTT & 61 & 60 & - \\
\hline NANOG total & hNANOG-S286 & CCTATGCCTGTGATTTGTGG & hNANOG-AS503 & TGTTTCTTGACTGGGACCTTG & 218 & 62 & - \\
\hline OCT4 total & hPOU5F1-S1165 & GACAGGGGGAGGGGAGGAGCTAGG & $\begin{array}{l}\text { hPOU5F1- } \\
\text { AS1283 }\end{array}$ & СTTCCCTCCAACCAGTTGCCCCAAAC & 144 & 62 & - \\
\hline OCT4 tg & hPOU5F1-pla-S & CATTCAAACTGAGGTAAGGG & hPOU5F1-pla-AS & TAGCGTAAAAGGAGCAACATAG & 124 & 62 & - \\
\hline $\mathrm{SO} \times 2 \mathrm{tg}$ & hSOX2-pla-S & TTCACATGTCCCAGCACTACCAGA & hSOX2-pla-AS & TाTGTTGACAGGAGCGACAAT & 111 & 62 & - \\
\hline KLF4 tg & hKLF4-pla-S & CCACCTCGCCTTACACATGAAGA & hKLF4-pla-AS & TAGCGTAAAAGGAGCAACATAG & 156 & 62 & - \\
\hline L-MYC tg & hL-MYC-pla-S & GGCTGAGAAGAGGATGGCTAC & hL-MYC-pla-AS & TाTGTTGACAGGAGCGACAAT & 122 & 62 & - \\
\hline LIN28 tg & hLIN28-pla-S & AGCCATATGGTAGCCTCATGTCCGC & hLIN28-pla-AS & TAGCGTAAAAGGAGCAACATAG & 251 & 62 & - \\
\hline $\begin{array}{l}\beta \text {-ACTIN } \\
\text { (human } \\
\text { specific) }\end{array}$ & hb-ACTIN-S1062 & GATCAAGATCATTGCTCCTCCT & $\begin{array}{l}\text { hb-ACTIN- } \\
\text { AS1241 }\end{array}$ & GGGTGTAACGCAACTAAGTCA & 180 & 62 & - \\
\hline
\end{tabular}


on $10 \%$ SDS-PAGE and transferred to a nitrocellulose membrane. The blot was then probed with the following primary antibodies: $\beta$-ACTIN (mouse $\operatorname{IgG}_{1}, 1: 5000$, SigmaAldrich, USA), HB9 (mouse $\operatorname{IgG}_{1}, 1: 2000$, DSHB, USA), ISL-1 (mouse $\operatorname{IgG}_{2 \mathrm{a}}, 1: 2000$, DSHB, USA), and ChAT (goat IgG, 1:2000, Chemicon, USA). Signals were detected with HRP-conjugated secondary antibodies (Jackson ImmunoResearch laboratory Inc., USA) using an ECL Prime kit (Amersham Biosciences, USA). Quantitative analysis was performed using LAS4000 (Amersham biosciences, USA) and ImageJ software. The amount of protein loaded in each slot was normalized to $\beta$-ACTIN.

\section{Flow cytometry}

For flow cytometric analysis, 201B7-derived motor neurons were harvested 7 days after infection with the $H B 9^{e 438}:: V e$ nus lentivirus (10-11 days of monolayer differentiation) using TrypLE Select. The dissociated cells $\left(5 \times 10^{4}-1 \times 10^{5}\right.$ cells) were suspended in 50-100 $\mu$ l of Hanks' balanced salt solution (HBSS) (Thermo Fisher Scientific, USA) containing $2 \%$ fetal bovine serum, $10 \mathrm{mM}$ HEPES, and $1 \mu \mathrm{g} / \mathrm{ml}$ propidium iodide. The cells were then analyzed and sorted based on the expression of the HB9 $9^{e 438}:$ :Venus reporter using a FACS Aria III cell sorter (BD Biosciences, USA).

\section{Teratoma formation assay}

TIGE-9 and YFE-16 iPSCs were harvested in dissociation solution, collected into tubes, and centrifuged, and the resulting pellets were suspended in hESC medium with $10 \mu \mathrm{M}$ Y-27632 (Wako, Japan), a Rho-associated coiled-coil forming kinase (ROCK) inhibitor. Then, $1 \times 10^{5}-5 \times 10^{5}$ cells were injected into the testes of NOD/ SCID mice (Charles River, USA). At 8-10 weeks after injection, the tumors were dissected and fixed with PBS containing $4 \%$ PFA. Paraffin-embedded tissue was sliced and stained with hematoxylin and eosin.

\section{Additional file}

Additional file 1: Figure S1. Evaluation of hiPSCS, TIGE-9 and YFE-16 cells. a The genomic integration of episomal vectors was detected through quantitative genomic PCR with primers specific for EBNA-1. EBNA-1 copy numbers are normalized to the $\beta$-ACTIN copy number. The $E B N A-1$ copy numbers were presented as the relative copy numbers to those in fibroblasts transfected with three plasmid vectors for reprogramming and cultured for 6 days (fibroblast-TF day6) (see Materials and methods). b Transgene expression in established hiPSC clones was examined via quantitative RT-PCR and is presented as the copy number normalized to that of $\beta-A C T I N$. The expressions of indicated genes are presented as the relative expressions to those in fibroblast-TF day6. c The expression levels of the pluripotency markers OCT4 and NANOG in established hiPSC clones were determined through quantitative RTPCR analysis. d Immunocytochemical analysis of TIGE-9 and YFE-16 hiPSCs for OCT4, NANOG, Tra-1-60, and SSEA-4. Scale bar, $300 \mu \mathrm{m}$. e Hematoxylin and eosin staining of teratomas derived from TIGE-9 and YFE-16 hiPSCs. Scale bar, $200 \mu \mathrm{m}$. f Karyotype analysis of TIGE-9 and YFE-16 hiPSCs via G-banding analysis. (PNG $5285 \mathrm{~kb}$ )

\section{Abbreviations}

hPSC: Human pluripotent stem cell; hiPSC: Human induced pluripotent stem cell; hESC: Human embryonic stem cell; EB: Embryoid body.

\section{Competing interests}

H.O. is a paid member of the Scientific Advisory Board of SanBio Co., Ltd.

\section{Authors' contributions}

$\mathrm{DS}, \mathrm{HO}$, and $\mathrm{YO}$ conceived of and designed the experiments. DS performed most of the experiments and analyzed the data. KO, YDT, YI, CH, YM, ST, RO, $M S, A N$, and $Y O$ performed experiments and analyzed the data. YI generated the YFE-16 and TIGE-9 iPSCS. MO performed biopsies and provided HDFs. MD supported the research. DS, HO, and YO wrote the manuscript. All authors read and approved the final manuscript.

\section{Acknowledgments}

We are grateful to Dr. Hirofumi Suemori for providing KhES1 hESCs, Dr. Shinya Yamanaka for 201B7 hiPSCs, Dr. Wado Akamatsu for supporting iPSC establishment, Dr. Steven Goldman for the $H B 9^{e 438}$ enhancer element, Dr. Hiroyuki Miyoshi for lentiviral vectors, and Drs Hiroki Shinkai, Satoshi Niwa, Kazuko Kondoh, and Ayako Suzuki for technical and administrative assistance. We are also grateful to the members of the Okano and Okada laboratories for their encouragement and kind support. This work was supported by the Kanrinmaru-Project at Keio University; grants from the Practical Research

Project for Intractable Diseases of the Ministry of Health, Labour and Welfare (MHLW) and the Japan Agency for Medical Research and development (AMED); a Grant-in-Aid for Scientific Research (B); and a Grant-in-Aid for Challenging Exploratory Research from the Japan Society for the Promotion of Science (JSPS) to YO. This work was also supported by a Grant-in-Aid for Scientific Research in Innovative Areas (Foundation of Synapse Neurocircuit Pathology to YO; a Brain Protein Aging and Dementia Control to YO and HO) from the JSPS and the Japanese Ministry of Education, Culture, Sports, Science and Technology (MEXT); the Project for the Realization of Regenerative Medicine and Support for the Core Institutes for iPS cell research from the MEXT; a grant from the Program for Intractable Disease Research utilizing disease-specific iPS Cells from the Japan Science and Technology Agency (JST) and AMED to HO; and a Grant-in-Aid for JSPS Fellows to DS.

\section{Author details}

'Department of Neurology, Aichi Medical University School of Medicine, Aichi 480-1195, Japan. ${ }^{2}$ Department of Physiology, Keio University School of Medicine, Tokyo 160-8582, Japan. ${ }^{3}$ Department of Neurology, Nagoya University Graduate School of Medicine, Nagoya 466-8550, Japan. ${ }^{4}$ Department of Orthopedic Surgery, Nagoya University Graduate School of Medicine, Nagoya 466-8550, Japan. ${ }^{5}$ Division of Regenerative Medicine, Jikei University School of Medicine, Tokyo 105-8461, Japan. 'Department of Dermatology, Keio University School of Medicine, Tokyo 160-8582, Japan. ${ }^{7}$ Integrated Technology Research Laboratories, Pharmaceutical Research Division, Takeda Pharmaceutical Company Limited, Kanagawa 251-8555, Japan.

Received: 7 November 2015 Accepted: 25 November 2015 Published online: 01 December 2015

\section{References}

1. Takahashi K, Tanabe K, Ohnuki M, Narita M, Ichisaka T, Tomoda K, et al. Induction of pluripotent stem cells from adult human fibroblasts by defined factors. Cell. 2007;131(5):861-72. doi:10.1016/j.cell.2007.11.019.

2. Egawa N, Kitaoka S, Tsukita K, Naitoh M, Takahashi K, Yamamoto T, et al. Drug screening for ALS using patient-specific induced pluripotent stem cells. Sci Transl Med. 2012;4(145):145ra04. doi:10.1126/scitranslmed.3004052.

3. Mica Y, Lee G, Chambers SM, Tomishima MJ, Studer L. Modeling neural crest induction, melanocyte specification, and disease-related pigmentation defects in hESCs and patient-specific iPSCs. Cell reports. 2013;3(4):1140-52. doi:10.1016/j.celrep.2013.03.025.

4. Nihei Y, Ito D, Okada Y, Akamatsu W, Yagi T, Yoshizaki T, et al. Enhanced aggregation of androgen receptor in induced pluripotent stem cell-derived neurons from spinal and bulbar muscular atrophy. The Journal of biological chemistry. 2013;288(12):8043-52. doi:10.1074/jbc.M112.408211. 
5. Osafune K, Caron L, Borowiak M, Martinez RJ, Fitz-Gerald CS, Sato Y, et al. Marked differences in differentiation propensity among human embryonic stem cell lines. Nat Biotechnol. 2008;26(3):313-5. doi:10.1038/nbt1383.

6. Okada Y, Matsumoto A, Shimazaki T, Enoki R, Koizumi A, Ishii S, et al. Spatiotemporal recapitulation of central nervous system development by murine embryonic stem cell-derived neural stem/progenitor cells. Stem Cells. 2008;26(12):3086-98. doi:10.1634/stemcells.2008-0293.

7. Nori S, Okada Y, Yasuda A, Tsuji O, Takahashi Y, Kobayashi Y, et al. Grafted human-induced pluripotent stem-cell-derived neurospheres promote motor functional recovery after spinal cord injury in mice. Proc Natl Acad Sci U S A. 2011;108(40):16825-30. doi:10.1073/pnas.1108077108.

8. Chambers SM, Fasano CA, Papapetrou EP, Tomishima M, Sadelain M, Studer L. Highly efficient neural conversion of human ES and iPS cells by dual inhibition of SMAD signaling. Nat Biotechnol. 2009:27(3):275-80. doi:10.1038/nbt.1529.

9. Suemori H, Yasuchika K, Hasegawa K, Fujioka T, Tsuneyoshi N, Nakatsuji N. Efficient establishment of human embryonic stem cell lines and long-term maintenance with stable karyotype by enzymatic bulk passage. Biochem Biophys Res Commun. 2006;345(3):926-32. doi:10.1016/j.bbrc.2006.04.135

10. Hashimoto N, Kiyono T, Wada MR, Shimizu S, Yasumoto S, Inagawa M. Immortalization of human myogenic progenitor cell clone retaining multipotentiality. Biochem Biophys Res Commun. 2006;348(4):1383-8. doi:10.1016/j.bbrc.2006.08.006.

11. Hashimoto N, Kiyono T, Wada MR, Umeda R, Goto Y, Nonaka I, et al. Osteogenic properties of human myogenic progenitor cells. Mech Dev. 2008;125(3-4):257-69. doi:10.1016/j.mod.2007.11.004.

12. Naujok O, Lentes J, Diekmann U, Davenport C, Lenzen S. Cytotoxicity and activation of the Wnt/beta-catenin pathway in mouse embryonic stem cells treated with four GSK3 inhibitors. BMC research notes. 2014;7:273. doi:10.1186/1756-0500-7-273

13. Surmacz B, Fox H, Gutteridge A, Fish P, Lubitz S, Whiting P. Directing differentiation of human embryonic stem cells toward anterior neural ectoderm using small molecules. Stem Cells. 2012;30(9):1875-84. doi:10.1002/stem.1166.

14. Nagai T, Ibata K, Park ES, Kubota M, Mikoshiba K, Miyawaki A. A variant of yellow fluorescent protein with fast and efficient maturation for cell-biological applications. Nat Biotechnol. 2002;20(1):87-90. doi:10.1038/nbt0102-87.

15. Nakano T, Windrem M, Zappavigna V, Goldman SA. Identification of a conserved 125 base-pair Hb9 enhancer that specifies gene expression to spinal motor neurons. Dev Biol. 2005;283(2):474-85. doi:10.1016/j.ydbio.2005. 04.017.

16. Eiraku M, Watanabe K, Matsuo-Takasaki M, Kawada M, Yonemura S, Matsumura $M$, et al. Self-organized formation of polarized cortical tissues from ESCs and its active manipulation by extrinsic signals. Cell Stem Cell. 2008;3(5):519-32. doi:10.1016/j.stem.2008.09.002.

17. Reinhardt P, Glatza M, Hemmer K, Tsytsyura Y, Thiel CS, Hoing S, et al. Derivation and expansion using only small molecules of human neural progenitors for neurodegenerative disease modeling. PLoS One. 2013;8(3), e59252. doi:10.1371/journal.pone.0059252.

18. Du ZW, Chen H, Liu H, Lu J, Qian K, Huang CL, et al. Generation and expansion of highly pure motor neuron progenitors from human pluripotent stem cells. Nat Commun. 2015;6:6626. doi:10.1038/ncomms7626.

19. Zeng H, Guo M, Martins-Taylor K, Wang X, Zhang Z, Park JW, et al. Specification of region-specific neurons including forebrain glutamatergic neurons from human induced pluripotent stem cells. PLoS One. 2010;5(7), e11853. doi:10.1371/journal.pone.0011853.

20. Amoroso MW, Croft GF, Williams DJ, O'Keeffe S, Carrasco MA, Davis AR, et al. Accelerated high-yield generation of limb-innervating motor neurons from human stem cells. The Journal of neuroscience : the official journal of the Society for Neuroscience. 2013;33(2):574-86. doi:10.1523/jneurosci.0906-12.2013.

21. Chen X, Li Q, Xu H, Yin ZQ. Sodium iodate influences the apoptosis, proliferation and differentiation potential of radial glial cells in vitro. Cellular physiology and biochemistry: international journal of experimental cellular physiology, biochemistry, and pharmacology. 2014;34(4):1109-24. doi:10.1159/000366325.

22. Hirabayashi $Y$, Itoh $Y$, Tabata $H$, Nakajima K, Akiyama T, Masuyama N, et al. The Wnt/beta-catenin pathway directs neuronal differentiation of cortical neural precursor cells. Development. 2004;131(12):2791-801. doi:10.1242/dev.01165.

23. Shimizu T, Kagawa T, Inoue T, Nonaka A, Takada S, Aburatani H, et al. Stabilized beta-catenin functions through TCF/LEF proteins and the Notch/ RBP-Jkappa complex to promote proliferation and suppress differentiation of neural precursor cells. Mol Cell Biol. 2008;28(24):7427-41. doi:10.1128/ MCB.01962-07.
24. Ohta E, Nihira T, Uchino A, Imaizumi Y, Okada Y, Akamatsu W, et al. I2020T mutant LRRK2 iPSC-derived neurons in the Sagamihara family exhibit increased Tau phosphorylation through the AKT/GSK-3beta signaling pathway. Hum Mol Genet. 2015;24(17):4879-900. doi:10.1093/hmg/ddv212.

25. Miller JD, Ganat YM, Kishinevsky S, Bowman RL, Liu B, Tu EY, et al. Human iPSC-based modeling of late-onset disease via progerin-induced aging. Cell Stem Cell. 2013;13(6):691-705. doi:10.1016/j.stem.2013.11.006.

26. Koch P, Breuer P, Peitz M, Jungverdorben J, Kesavan J, Poppe D, et al. Excitationinduced ataxin-3 aggregation in neurons from patients with Machado-Joseph disease. Nature. 2011;480(7378):543-6. doi:10.1038/nature10671.

27. Numasawa-Kuroiwa Y, Okada Y, Shibata S, Kishi N, Akamatsu W, Shoji M, et al. Involvement of ER stress in dysmyelination of Pelizaeus-Merzbacher Disease with PLP1 missense mutations shown by iPSC-derived oligodendrocytes. Stem cell reports. 2014;2(5):648-61. doi:10.1016/j.stemcr. 2014.03.007.

28. Takazawa T, Croft GF, Amoroso MW, Studer L, Wichterle H, Macdermott AB. Maturation of spinal motor neurons derived from human embryonic stem cells. PLoS One. 2012;7(7), e40154. doi:10.1371/journal.pone.0040154.

29. Huang Z, Wu Q, Guryanova OA, Cheng L, Shou W, Rich JN, et al. Deubiquitylase HAUSP stabilizes REST and promotes maintenance of neural progenitor cells. Nat Cell Biol. 2011;13(2):142-52. doi:10.1038/ncb2153.

30. Otaegi G, Pollock A, Hong J, Sun T. MicroRNA miR-9 modifies motor neuron columns by a tuning regulation of FoxP1 levels in developing spinal cords. The Journal of neuroscience : the official journal of the Society for Neuroscience. 2011;31(3):809-18. doi:10.1523/jneurosci.4330-10.2011.

31. Kwan KY, Lam MM, Johnson MB, Dube U, Shim S, Rasin MR, et al. Speciesdependent posttranscriptional regulation of NOS1 by FMRP in the developing cerebral cortex. Cell. 2012;149(4):899-911. doi:10.1016/j.cell.2012.02.060.

32. Tcherkezian J, Brittis PA, Thomas F, Roux PP, Flanagan JG. Transmembrane receptor DCC associates with protein synthesis machinery and regulates translation. Cell. 2010;141(4):632-44. doi:10.1016/j.cell.2010.04.008.

33. Arber S, Han B, Mendelsohn M, Smith M, Jessell TM, Sockanathan S. Requirement for the homeobox gene $\mathrm{Hb} 9$ in the consolidation of motor neuron identity. Neuron. 1999;23(4):659-74.

34. Okita K, Matsumura Y, Sato Y, Okada A, Morizane A, Okamoto S, et al. A more efficient method to generate integration-free human iPS cells. Nat Methods. 2011;8(5):409-12. doi:10.1038/nmeth.1591.

35. Okada Y, Shimazaki T, Sobue G, Okano H. Retinoic-acid-concentrationdependent acquisition of neural cell identity during in vitro differentiation of mouse embryonic stem cells. Dev Biol. 2004;275(1):124-42. doi:10.1016/j. ydbio.2004.07.038

\section{Submit your next manuscript to BioMed Central and we will help you at every step:}

- We accept pre-submission inquiries

- Our selector tool helps you to find the most relevant journal

- We provide round the clock customer support

- Convenient online submission

- Thorough peer review

- Inclusion in PubMed and all major indexing services

- Maximum visibility for your research

Submit your manuscript at www.biomedcentral.com/submit
C BioMed Central 